\title{
TECNOLOGIA COMO FERRAMENTA PEDAGÓGICA PARA O \\ ENSINO-APRENDIZAGEM DA ORTOGRAFIA: ESTUDO COMPARATIVO ENTRE DOIS APLICATIVOS
}

\section{TECHNOLOGY AS PEDAGOGICAL TOOL FOR TEACHING- LEARNING IN ORTHOGRAPHY: A COMPARATIVE STUDY BETWEEN TWO APPLICATIONS}

\author{
Vera Aparecida Cordeiro Siqueira* \\ Adriana Nascimento Bodolay** \\ Luciana Pereira Assis ${ }^{* * *}$
}

\begin{abstract}
RESUMO: Este artigo tem como objetivo apresentar resultados do uso da tecnologia como auxiliar do professor na sala de aula e facilitador do processo do ensino-aprendizagem da ortografia, no que se refere à memorização das palavras que possuem relação irregular entre grafema-fonema. $\mathrm{O}$ estudo foi feito no formato de censo, com 50 crianças de 8 anos, de uma escola pública, divididas em grupo teste e grupo controle. Compararam-se os resultados obtidos entre dois aplicativos com a mesma finalidade, aplicandose um pré-teste e um pós-teste. Notou-se que o aplicativo Grapphia contribuiu para melhoria da memorização das palavras, demonstrando que esse pode se tornar uma ferramenta pedagógica no ensino de ortografia.
\end{abstract}

Palavras-chave: Tecnologias digitais. Língua Portuguesa. Ensino de ortografia.

ABSTRACT: This paper aims at presenting results from use of technology as an assistant to teachers in classroom and facilitator for orthography teaching-learning process, regarding the memorization of words that have an irregular relationship between grapheme and phoneme. The study was carried out under a census format, with 50 8-years-old children from a public school, split into a test group and a control group. The results were compared between two applications for the same purpose, applying a pre-test and a post-test. It was found that Grapphia application contributed on the improvements of words memorization, which is an evidence that it can become a pedagogical tool in orthography teaching.

Keywords: Digital technologies. Portuguese language. Orthography teaching.

\section{Introdução}

O presente artigo apresenta os resultados obtidos em um experimento com dois jogos educacionais digitais: Grapphia e Forma Palavras, aplicativos desenvolvidos para auxiliar no ensino-aprendizagem da ortografia, feito com crianças de 8 anos, do terceiro ano do Ensino Fundamental. De forma mais específica, investigamos se o aplicativo Grapphia contribui para uma maior memorização das palavras com relação irregular entre grafema/fonema. Essas palavras são aquelas que não possuem um princípio gerativo que justifique o uso de um ou outro grafema concorrente.

\footnotetext{
* Mestre em Educação pela Universidade Federal dos Vales do Jequitinhonha e Mucuri (2019). Professora de Língua Portuguesa. E-mail: vera.siqueira1@gmail.com

** Doutora em Estudos Linguísticos (2009) pela UFMG. Professora Adjunta do Curso de Letras da UFVJM. Atua no Programa de Pós-Graduação em Educação. E-mail: adriananbodolay@gmail.com

*** Doutora em Engenharia Elétrica (2013) pela UFMG. Professora Adjunta do Curso de Sistema de Informação da UFVJM. Atua no Programa de Pós-Graduação em Educação. E-mail: lupassis@gmail.com
} 
Um exemplo dessa relação é o vocábulo casa. Nesse caso específico, utilizamos o grafema s para representar o fonema /z/. Entretanto, para uma criança em fase de inicial do letramento, e que recentemente tenha sido alfabetizada, a palavra casa é passível de ser registrada com desvio, fundamentalmente porque nessa fase a criança tende a tomar como base a hipótese de correspondência biunívoca (LEMLE, 2009) entre letra e som. A estratégia de ensino desse grupo de palavras, segundo Alvarenga (1995) e Morais (2003), na falta de uma norma para explicar o emprego de um determinado grafema, é o desenvolvimento de atividades sistemáticas de memorização.

Para esse grupo de palavras, as irregularidades, Alvarenga (1995) propõe o seu ensino a partir de jogos. Com o avanço das tecnologias digitais, a perspectiva basilar para este trabalho é de que o ensino de ortografia pode ser tratado de forma lúdica, com o auxílio das Tecnologias Digitais de Informação e Comunicação (TDICs).

Tomando os estudos citados como base, foi criado o jogo digital educacional ortográfico Grapphia, que apresenta uma metodologia para estimular a memorização. Trata-se de um jogo multimodal, pois a criança, além de ouvir as palavras empregadas de forma contextualizada em um conto, também pode vê-las e escrevê-las e repeti-las oralmente, durante as atividades propostas.

A proposta do Grapphia considera que é preciso que um jogo digital seja mais do que um simples instrumento divertido e lúdico, que aguce a curiosidade e vontade de brincar. O aplicativo foi desenvolvido a partir dos trabalhos de Morais (2003), Zorzi (2003), Cagliari (2005), Belloni (2008), Lemle (2009) e Rojo (2013). As reflexões apontadas por esses autores orientam a fundamentação teórico-metodológica dessa ferramenta, a partir dos princípios de se ter o professor como mediador do processo ensino-aprendizagem, bem como considera a relação entre o ambiente escolar e a tecnologia. Embora apresente tais características, cabe-nos questionar se esse aplicativo, de fato, contribui para aprendizagem da ortografia, considerando a importância de se aprender ortografia nas séries iniciais da escolarização.

$\mathrm{O}$ experimento aqui relatado é parte da pesquisa de mestrado (AUTOR X, 2019) e foi feito com duas turmas do terceiro ano dos Anos Iniciais do Ensino Fundamental, da Escola X, da cidade X. Buscamos avaliar, ainda, o Grapphia como uma ferramenta para o professor na sala de aula. É importante salientar que o aplicativo foi planejado na expectativa da cultura escolar, segundo a qual determinados conhecimentos sobre a língua devem estar consolidados pela criança em uma certa faixa etária.

Justificamos a importância deste estudo pautando-nos em argumentações e dados que tratam da relação da ortografia com as tecnologias digitais. Autores como Belloni (2008) e Rojo (2013) defendem que o uso das tecnologias e dos produtos que elas permitem desenvolver proporciona maiores possibilidades para a realização das atividades diárias, auxiliando o processo educativo. Nesse contexto, observamos a existência de uma gama de dispositivos disponíveis que podem se tornar ferramentas de grande potencial, contribuindo para o desenvolvimento de diversos conteúdos e, principalmente, da ortografia.

Do ponto de vista didático, é interessante colocar em questão que a utilização de recursos digitais altera, de certa maneira, o fazer pedagógico. Segundo Rojo (2013), dispomos de novas tecnologias e ferramentas de leitura e escrita que são capazes dar outros significados à dinâmica da sala de aula. Portanto, torna-se válido registrar que, do nosso ponto de vista, cabe à tecnologia o papel de complementar a abordagem dada 
ao conteúdo pelo professor, tornando-se um elemento que agrega possibilidades de aprendizagem. Entretanto, sem a devida capacitação do docente para essa concepção, as tecnologias podem se tornar apenas uma tarefa figurativa.

Ainda em relação à presença das TDICs em sala de aula, atentamos para a existência de uma infinidade de jogos digitais educativos criados para crianças em idades cada vez menores. De fato, nota-se uma habilidade das crianças nascidas na era de dispositivos móveis para lidar com esse equipamento. Essa percepção, aliada à atratividade das crianças pelos jogos, torna o jogo digital educacional um mecanismo que pode auxiliar o professor no ensino da ortografia na fase de pós-alfabetização.

\section{Ensino de ortografia}

A ortografia faz parte dos conteúdos escolares, embora não seja parte da gramática da língua. Os documentos que orientam a formulação do currículo preconizam que o seu ensino é um conhecimento necessário e relevante dentro da disciplina de Língua Portuguesa (LP). As primeiras obras de referência são datadas de 1911, para o Português de Portugal, e de 1943 para o Português do Brasil (MORAIS, 2007). Anteriormente a essa realidade, os usuários da língua grafavam as palavras tal como se achasse ser a forma correta. Por essa razão, Morais (2007) afirma que a ortografia é uma convenção social: um modo encontrado pela sociedade para unificar a forma de escrever uma palavra, para que pessoas de diferentes regiões e culturas consigam entender o uso de determinada palavra no texto em norma-padrão, facilitando, assim, a sua interpretação.

Uma vez que a LP é anterior ao registro ortográfico, podemos afirmar que não há uma relação de dependência da língua para com a ortografia. No entanto, observando a questão sob o prisma inverso, nota-se que, para a criação de normas ortográficas, é necessário o conhecimento de diversos componentes, como os princípios fonológicos e etimológicos, ou mesmo sintáticos e semânticos. Morais (2007, p. 14) acrescenta: "Numa língua como o Português, vemos hoje que a norma ortográfica envolve não só a definição das letras autorizadas para escrever cada palavra, como também a segmentação destas no texto e o emprego da acentuação".

Assim, trata-se de um conteúdo relevante dentro da disciplina de LP para que o aluno consiga escrever textos seguindo a modalidade socialmente prestigiada da língua. A escrita correta das palavras possibilita que se consiga ler e, consequentemente, entender o que foi escrito, independentemente da variante linguística.

Observamos nesse cenário que os docentes, ao ensinarem ortografia, atravessam vários dilemas e um deles provém do fato de não existir uma linearidade ou uma regra única a ser seguida. Muitas vezes não há resposta, por exemplo, do porquê de uma palavra ser escrita com s e não com z, apesar de a pronúncia não se diferenciar, como é o caso das palavras casa e beleza: ambas possuem em sua pronúncia som [z], mas são grafadas respectivamente com s e $\mathrm{z}$.

Esse fenômeno é tratado na literatura por Morais (2007) e Lemle (2009) como casos de regularidades e irregularidades. As regularidades são o grupo de palavras que possuem relação regular entre grafema-fonema. São determinadas por certas regras e podem ser aprendidas através da compreensão de comportamentos linguísticos, de ordem fonológica e morfossintática. Por outro lado, as irregularidades são o grupo de 
palavras que possuem relação irregular entre grafema-fonema e não possuem um princípio gerativo e, dessa forma, é necessário que sejam memorizadas (MORAIS, 2007). Interessou-nos, neste trabalho, esse último grupo.

Reafirmamos que o propósito desta pesquisa foi investigar se o uso de aplicativo digital educativo, desenvolvido para o ensino de ortografia, proporciona uma memorização das palavras com relação irregular entre grafema-fonema da Língua Portuguesa. Para tanto, partimos do princípio de que a presença da tecnologia na sala de aula vem modificando a forma de ensinar, aprender e apreender os conteúdos, além de proporcionar significativas inovações, como, por exemplo, a possibilidade de trabalhar a partir de várias mídias. O trabalho do professor, então, não precisa se restringir às mídias impressas, sendo possível incentivar a colaboração e a interação, em que os alunos deixam de serem ouvintes e passam a serem agentes construtores do conhecimento (ROJO, 2013).

Nesse sentido, questionamos se o surgimento de novas metodologias aliadas às tecnologias poderia auxiliar e facilitar o ensino de determinada disciplina. Belloni (2008) é defensora desse ponto de vista quando afirma que é essencial que tenhamos consciência de que a integração da tecnologia à educação já não é uma opção, pois as tecnologias estão no mundo, modificando todos os aspectos da vida social e econômica, competindo ao campo educacional integrá-las e tirar de suas potencialidades comunicacionais e pedagógicas o melhor proveito (BELLONI, 2008, p. 104). Além disso, cabe salientar que as tecnologias deixaram de ser uma proposta para tornarem-se elementos componentes de uma nova ferramenta de ensino/aprendizagem.

Para caracterizar de maneira mais clara a presença constante da tecnologia na educação, consideramos importante citar que os jogos digitais educacionais são encontrados em números cada vez maiores. Esses, que visam auxiliar as várias disciplinas, dentre elas a Língua Portuguesa, apresentam-se de forma gratuita por meio de diversos aplicativos, ou mesmo de forma paga em plataformas, ou ainda estão disponíveis nas lojas de aplicativos.

Os jogos digitais educacionais potencializam as práticas educativas e despertam o olhar do educando para a língua materna. Além disso, apresentam como características positivas uma maior interação entre professor e aluno, dos alunos entre eles, tornando reais as possibilidades de aplicação do que se aprende em sala de aula, desenvolvem os sentidos, a coordenação motora, a atenção e apresentam vários mecanismos que visam à memorização.

Um ponto fundamental desta pesquisa foi, portanto, trazer essa discussão para o âmbito acadêmico, de forma indagadora. De modo a analisar se o jogo digital educativo é uma metodologia que poderá alcançar resultados significativos para o ensino de ortografia, em especial, nos casos das palavras com relação irregular entre grafema-fonema, selecionamos dois jogos que se propõem a essa finalidade.

\section{Os jogos digitais Grapphia e Forma palavras}

Conforme apresentado, este estudo se volta especialmente para análise dos primeiros resultados do jogo Grapphia, desenvolvido por professores da Universidade $\mathrm{X}$. Trata-se de um aplicativo para dispositivos móveis que tem como objetivo principal auxiliar e facilitar o ensino de ortografia através da prática da memorização nos casos 
das palavras com irregularidades na forma gráfica. Possui características distintas da maioria dos jogos encontrados atualmente, o que pode ser um diferencial no ensino do conteúdo em questão.

Esse jogo tem como suporte o celular, dispositivo móvel, de fácil manuseio e portabilidade, além do diferencial, que é apresentar as dificuldades ortográficas inseridas em um contexto. Listamos no Quadro 1 , a seguir, quatro ${ }^{1}$ das dificuldades ortográficas que envolvem irregularidades da LP que são tratadas no jogo:

Quadro 1 - Dificuldades ortográficas

\begin{tabular}{|l|l|l|}
\hline Mundo do jogo GRAPPHIA & \multicolumn{1}{c|}{ Notação } & \multicolumn{1}{c|}{ Exemplo } \\
\hline PALHAÇO & a notação do som /s/ com S, Ç e C & seguro, cidade, açude \\
\hline FAZENDA & a notação do som /z/ com S/Z & gozado, casa \\
\hline SOL DE VERÃO & L/U Final de sílaba & sol, sal \\
\hline ZOOLÓGICO & a notação do som /g/ com G/J & gelo, jiló \\
\hline
\end{tabular}

Fonte: dados da pesquisa.

No jogo, são abordadas algumas das principais irregularidades que serão tratadas em diferentes fases, denominadas mundos. Nessas fases, a criança é apresentada, gradativamente, às palavras, no intuito de memorizá-las. Cada um desses mundos é representado por livros, os quais se encontram na tela inicial do aplicativo, conforme Fig 1.

São quatro mundos projetados para o aplicativo: o primeiro deles é denominado $A$ fazenda, que aborda a notação do som /z/ com a oposição dos grafemas $\mathrm{S} / \mathrm{Z}$, como é o caso das palavras paisagem, fazenda, paraíso; o segundo, por sua vez, é o mundo do Zoológico, no qual se observa a notação do fonema /Z/ com os grafemas G/J, como é o exemplo das palavras girafa, pajé, viagem; já o terceiro mundo é o Sol de verão, em que se trata de $\mathrm{L} / \mathrm{U}$ final de sílaba, situação apresentada nas palavras varal, chapéu, farol; por fim, o quarto mundo, intitulado Palhaço, trabalha a notação do fonema /s/ com S, Ç e C, como exemplo as palavras bagunçam, diversão, palhaço.

Um diferencial está no fato de se contextualizarem as palavras dentro de um conto em que aquelas palavras são colocadas como parte de um todo e não isoladamente, como tradicionalmente são estudados os grupos ortográficos. Logo, o Grapphia segue as orientações dos PCN (1997), documento que ratifica que a contextualização ainda deve ser feita de forma a relacionar as várias disciplinas, mostrando ao aluno a utilidade do que se aprende na realidade:

O professor, considerando a multiplicidade de conhecimentos em jogo nas diferentes situações, pode tomar decisões a respeito de suas intervenções e da maneira como tratará os temas, de forma a propiciar aos alunos uma abordagem mais significativa e contextualizada (BRASIL, 1997, p. 44).

Confirmando essa ideia, Mattar (2010) afirma que, na atualidade, a educação está dividida: de um lado, o ensino de conteúdos totalmente descontextualizados; de outro, o aprendizado que ocorre por meio de simulações que o próprio aluno ajuda a elaborar, de forma ativa e colaborativa. Isso serve de base para a reflexão que, na

\footnotetext{
${ }^{1}$ É intenção dos criadores do jogo aumentar o número de dificuldades a serem abordadas no jogo.
} 
escola, os alunos estudam conteúdo sem compreender ao certo em que situações irão empregá-los. A partir disso, Mattar (2010) concorda que estudar faz mais sentido se o discente puder aplicar o que aprende, isto é, senão em situações reais, em situações de simulação, que podem ser proporcionadas pelos jogos.

Destaca-se, também, a multimodalidade dos textos do aplicativo apresentados ao aluno em forma de palavras, sons, imagens. Isso reafirma, portanto, a colocação de Demo (2008), que postula que as linguagens, na contemporaneidade, se tornaram multimodais; isso quer dizer que um texto possui vários recursos inclusos, como som, imagem, texto, animação, etc. Assim, um texto deve possuir todos esses elementos para ser atrativo e, caso não possua, as crianças, quando vão para a escola, se aborrecem porque a escola é lenta ao olhar do aluno (DEMO, 2008).

O jogo Grapphia apresenta um layout colorido, bem organizado, o que pode ser observado logo na tela inicial do jogo, conforme Fig.1. Apresenta também momentos interessantes, nos quais a criança tem opções que são cumulativas. Conforme foi apontado, os textos são multimodais: as palavras são lidas, observadas, ouvidas e reescritas. Após ouvir e ler o texto, a criança poderá jogar completando as lacunas das palavras apresentadas no texto com /s/ ou /z/, conforme Fig.2. Para o jogo, contamos com dois personagens, Julinha e Marcos (Fig. 3), entre os quais a criança deverá escolher um para ouvir a história do mundo que a mesma irá explorar.

Figura 1-Tela inicial do Grapphia

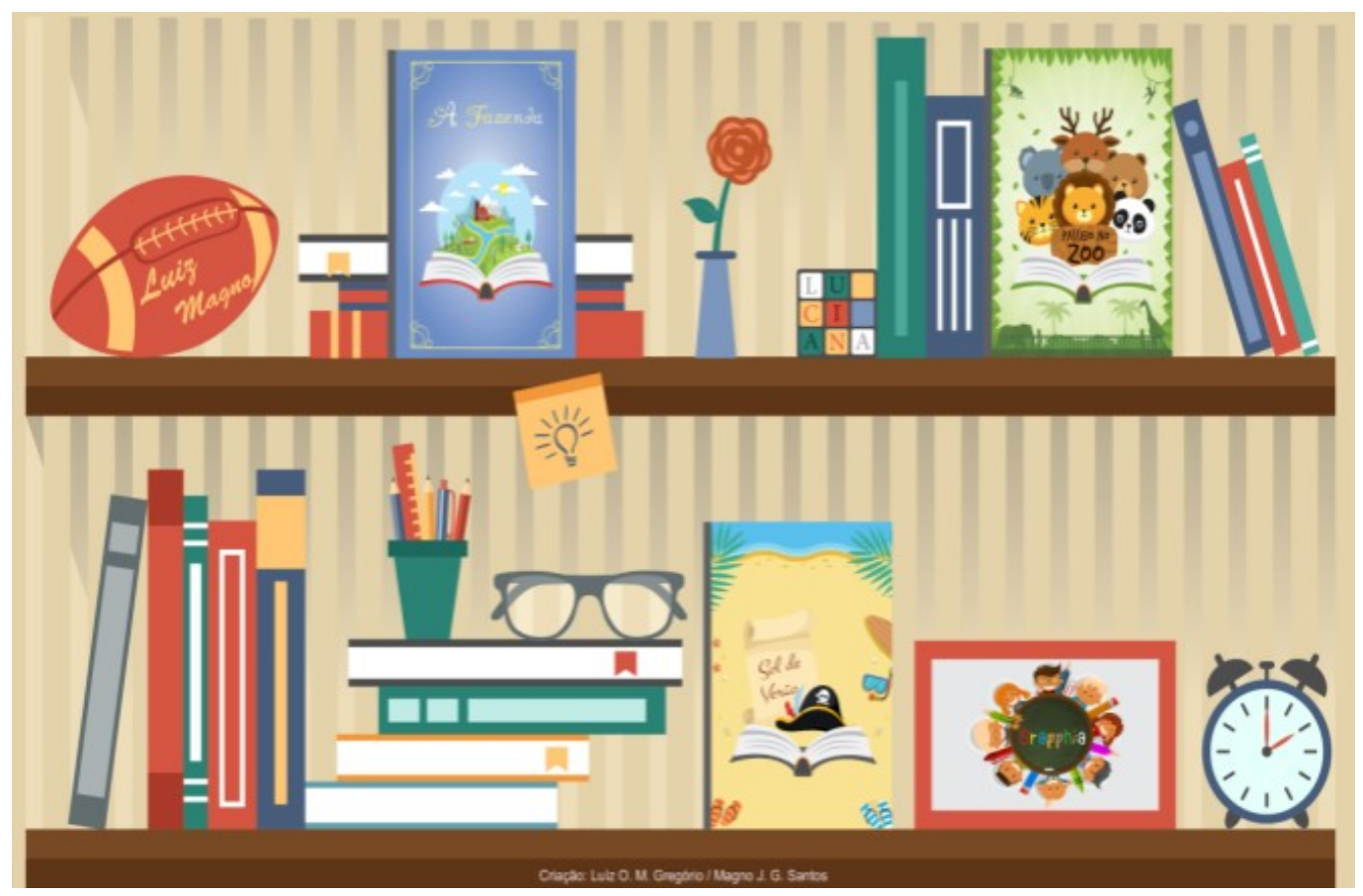

Fonte: Aplicativo Grapphia 
Figura 2-Tela do jogo

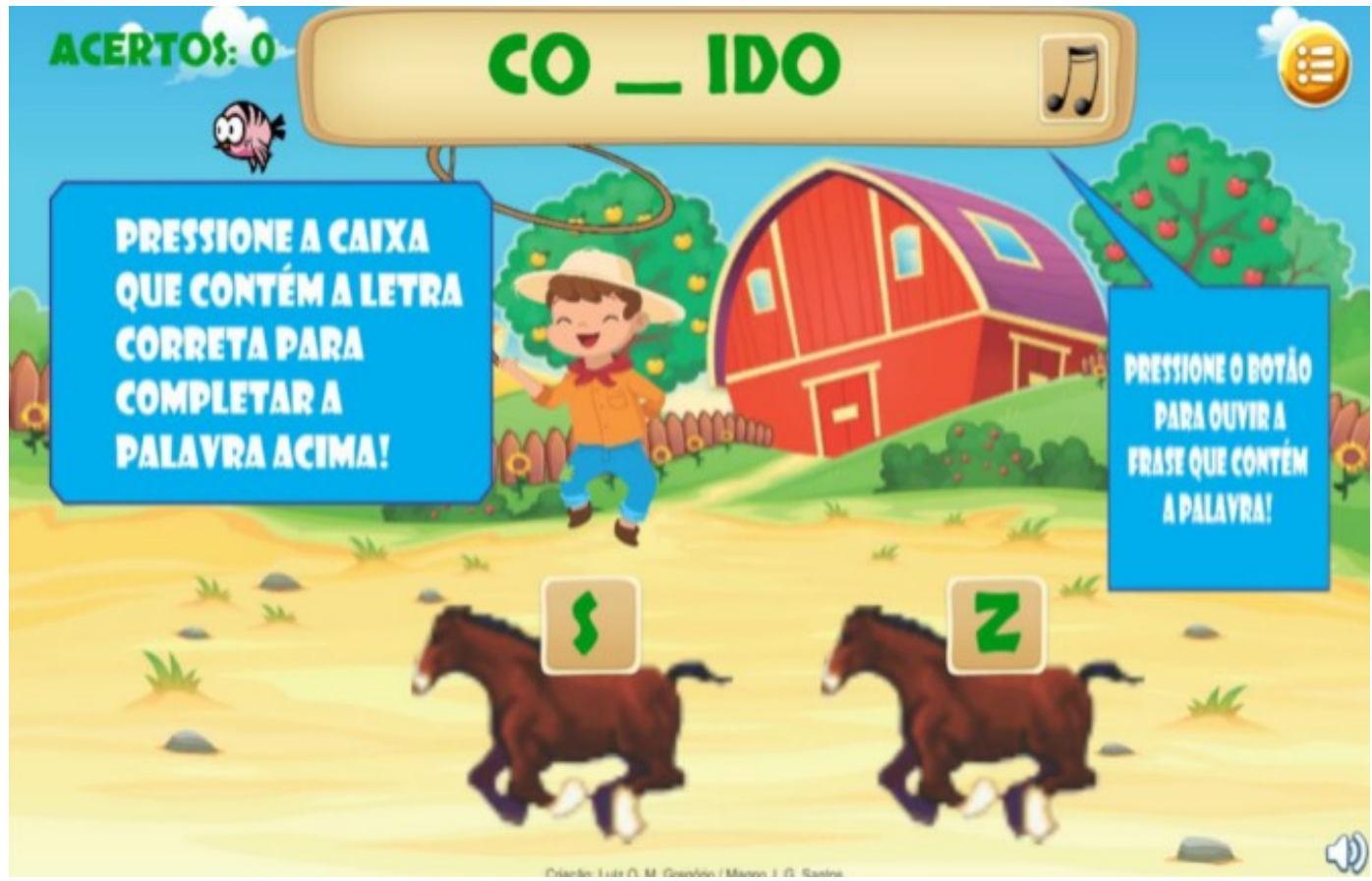

Fonte: Aplicativo Grapphia

Figura 3-Personagens

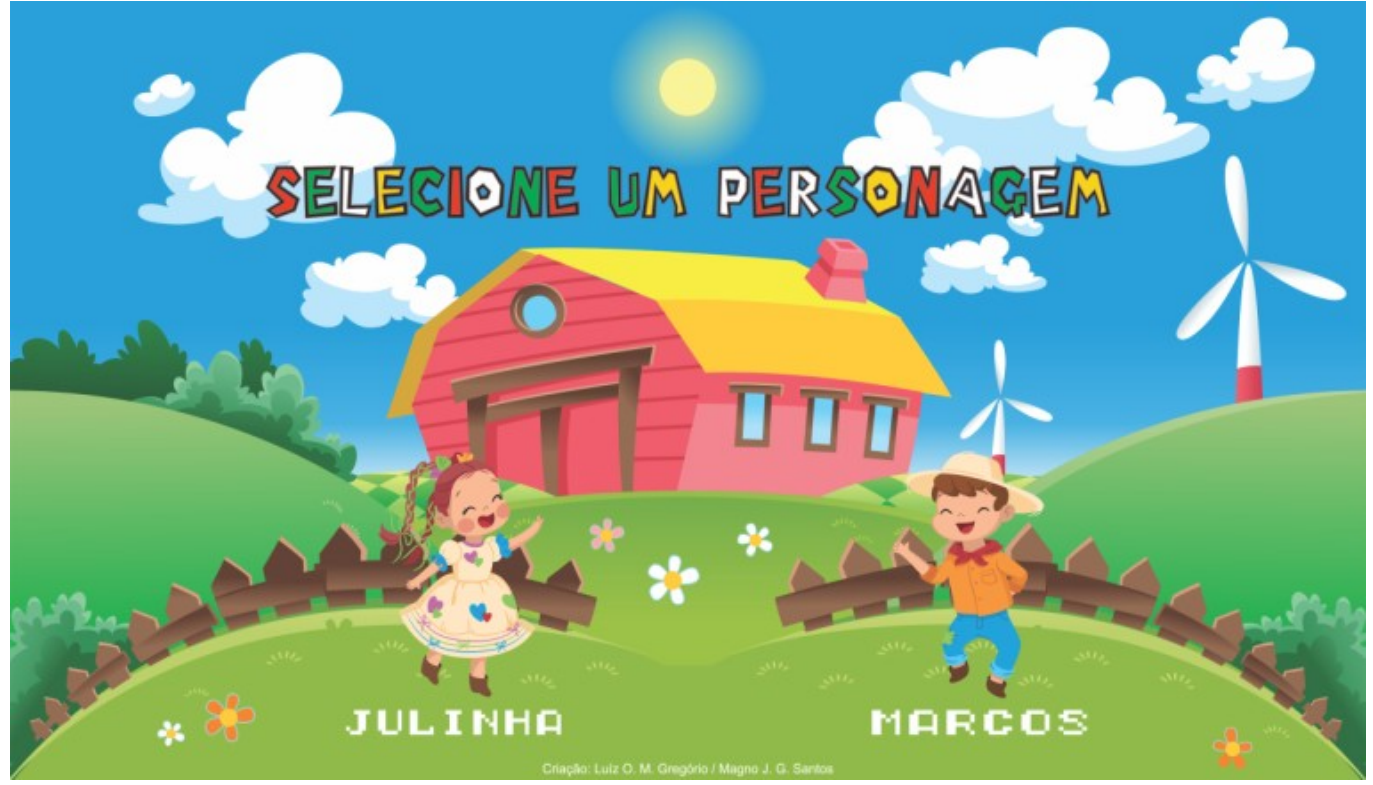

Fonte: Aplicativo Grapphia

Observamos que, além da visão, o educando também poderá desenvolver o sentido da audição, o que poderá dar à criança uma maior possibilidade de memorização das palavras. Daremos destaque ao contato visual proporcionado à criança pelo jogo 
Grapphia. É notável que, com a evolução no processo de aquisição da capacidade ortográfica, a memória visual também tem grande participação na maneira como os educandos fazem o registro escrito.

Barbosa et al. (2010) reiteram essa perspectiva dizendo que "é necessário que a criança seja levada a compreender o desenvolvimento de referências visuais ortográficas para que estes passem a influenciar o padrão da escrita". É importante mencionar que a memorização é apenas uma das possibilidades para uma ocorrência ortográfica precisa, mas é, também, um caminho para a outra vertente: o domínio e compreensão dos princípios gerativos, conforme afirmam Barbosa et al. (2010):

\begin{abstract}
A importância da memória visual, não está simplesmente na memorização da palavra escrita, por exemplo, por meio da cópia, mas da compreensão e domínio de princípios gerativos, ou seja, regras que vão determinar a grafia da palavra (Barbosa et al., 2010, p .604).
\end{abstract}

Nessa perspectiva, a criança deve ser não apenas capaz de memorizar a palavra, mas também deve entendê-la e saber utilizá-la nos textos que produz.

Ao fim de todas as etapas, o aplicativo armazena os dados relativos às palavras erradas e acertadas. Adiante, apresentamos uma análise que objetivou identificar qual dificuldade ortográfica foi mais memorizada, qual a menos memorizada e, por fim, buscamos explicar quais são os motivos que poderiam levar ao maior acerto ou erro das palavras apresentadas pelo jogo. Além disso, propusemos uma comparação dos resultados da atividade do texto lacunado feito pelas crianças que participarão dos grupos Teste e Controle. Esperamos, dessa maneira, avaliar os resultados obtidos por ambos os grupos, com dados relativos aos alunos do terceiro ano dos Anos Iniciais do Ensino Fundamental, que correspondem à faixa etária de 8 anos.

O segundo jogo utilizado neste trabalho, como distrator do grupo Controle, foi o Forma Palavras, por ser o mais próximo às características do jogo Grapphia. Apesar de ser recomendado para uma faixa etária diferente, ou seja, para crianças de 5 a 6 anos, esse jogo apresenta uma interface colorida, dinâmica, que usa letras que se movimentam. Esse jogo tem como objetivo o desenvolvimento da leitura e da escrita, e, para jogá-lo, o aluno deve organizar as lâmpadas, arrastando as letras, até formar a palavra indicada pelo desenho, conforme Fig. 4 e Fig. 5, abaixo: 
Figura 4- Palavra desorganizada

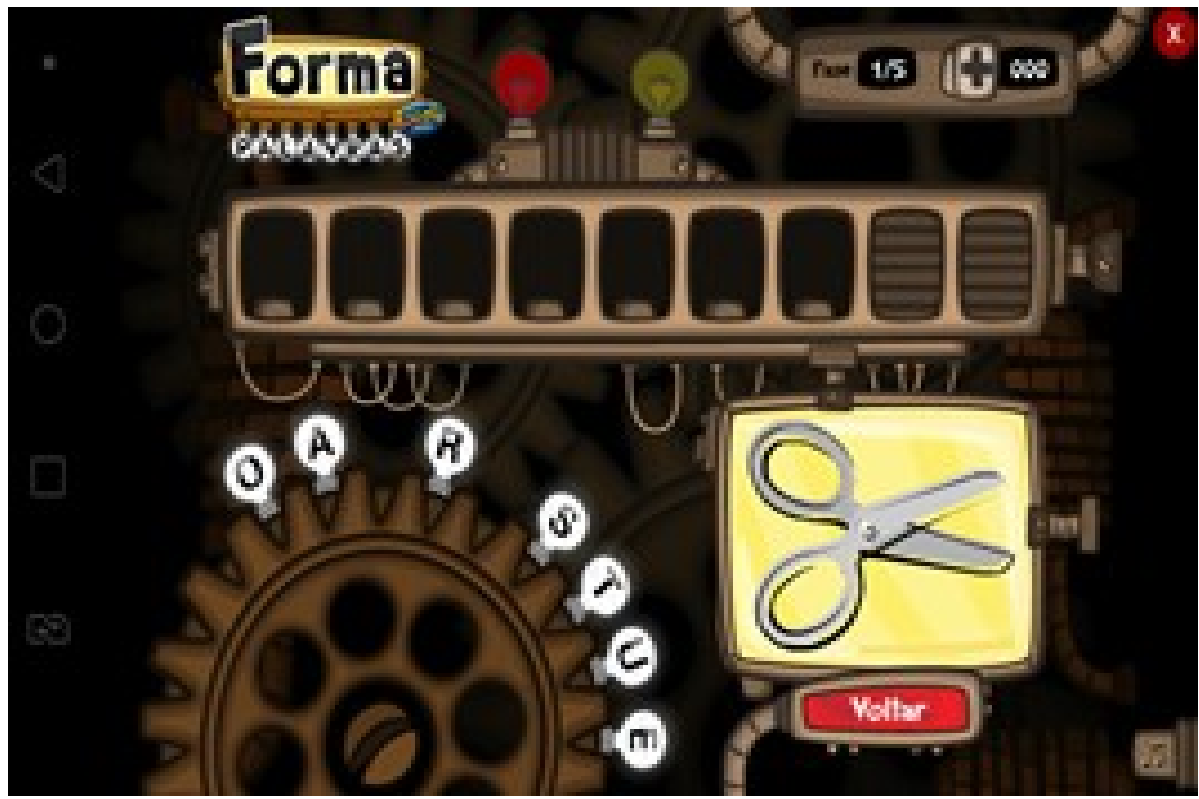

Figura 5- Palavra formada

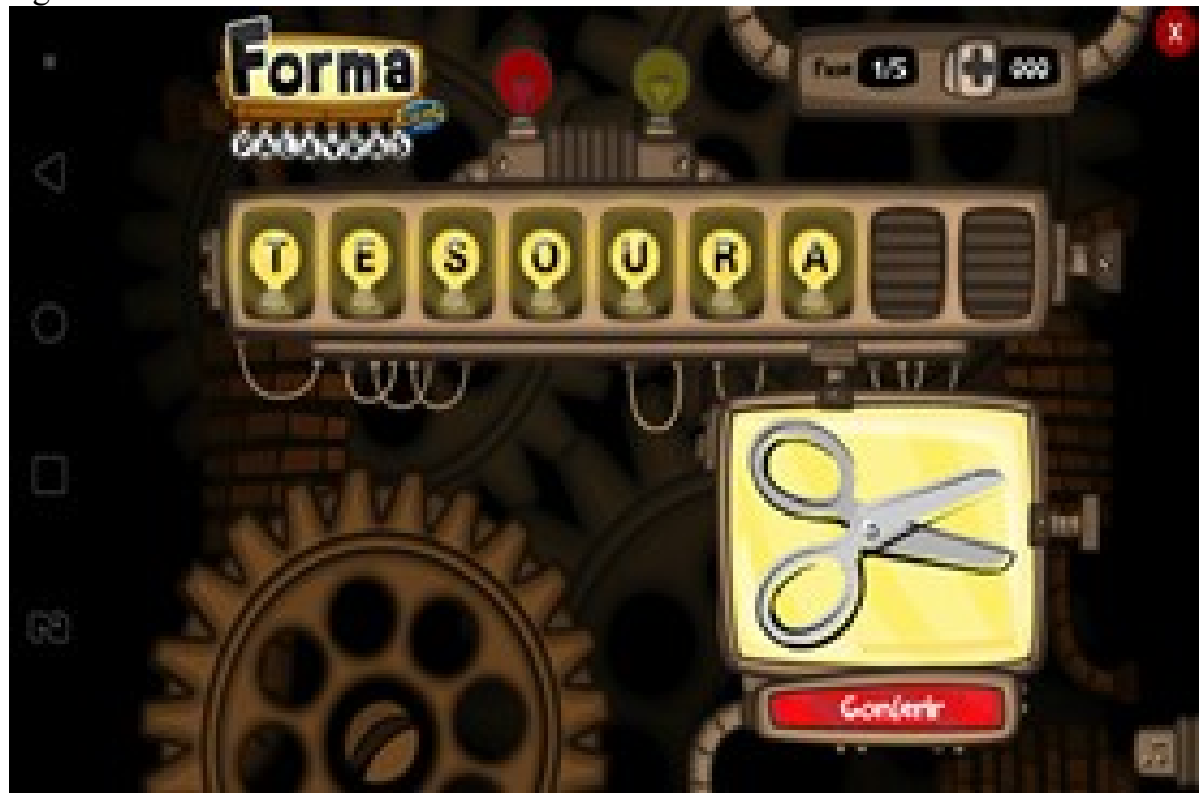

Fonte: Aplicativo Forma Palavras.

Se a palavra formada estiver correta, a luz verde localizada acima da palavra formada acenderá; caso isso não aconteça, a luz vermelha se acenderá, e o aluno terá novas chances. Também é possível que a criança confira se acertou ou errou a palavra.

Apesar de ser um jogo chamativo e interessante, foi possível observar que ele apresenta as palavras de maneira aleatória, não trabalhando, portanto, as dificuldades ortográficas com objetividade. Ressaltamos, também, que optamos por utilizar a tecnologia com todos os alunos da turma, visto que não é objetivo desta pesquisa fazer com que alguns se sentissem privilegiados em detrimento dos outros. 


\title{
4 Metodologia
}

Com a finalidade de respondermos às indagações feitas no decorrer desta pesquisa, escolhemos como método de investigação a pesquisa de campo de caráter experimental, com uma abordagem quantitativa. Podemos descrever como um dos tipos de pesquisa de campo, a pesquisa experimental, definida por Marconi e Lakatos (2008) como investigação de pesquisa empírica. Nessa mesma direção, Gonçalves (2001) argumenta que:

\begin{abstract}
A pesquisa de campo é o tipo de pesquisa que pretende buscar a informação diretamente com a população pesquisada. Ela exige do pesquisador um encontro mais direto. Nesse caso, o pesquisador precisa ir ao espaço onde o fenômeno ocorre, ou ocorreu e reunir um conjunto de informações a serem documentadas [...]. (GONÇALVES, 2001, p. 67).
\end{abstract}

Uma pesquisa quantitativa pode ser realizada de duas formas distintas: censo ou amostragem. Segundo Triola (2013), um censo é definido como uma coleção de dados relativos a todos os elementos de uma população. $\mathrm{Na}$ maioria das vezes, as pesquisas são realizadas via amostragem, examinando-se parte da população que se pretende investigar. Vários são os motivos que levam um pesquisador a optar por selecionar uma amostra ao invés de realizar um censo, tais como: economia, tempo, operacionalidade, entre outros. Contudo, quando a população é pequena, a característica é de fácil mensuração, a execução da pesquisa não é cara, bem como o tempo não é um problema, o pesquisador pode realizar um censo, pois, dessa maneira, obterá mais informações acerca da população que ele pretende investigar. Considerando esses aspectos, optamos por realizar um censo. Logo, trata-se de uma pesquisa de caráter censitário, do tipo experimental.

Nesta pesquisa, a população foi constituída por todos os alunos do terceiro ano dos Anos Iniciais do Ensino Fundamental, da Escola X, num total de 60 alunos, dos quais 50 concordaram ou estavam presentes e, portanto, participaram efetivamente da pesquisa. Desses, 25 alunos formaram o grupo Teste que teve acesso ao aplicativo digital Grapphia, e os outros 25 formaram o grupo Controle, que teve acesso ao jogo digital Forma Palavras. A alocação aleatória foi importante para a formação de grupos comparáveis, de modo que cada aluno tivesse a mesma probabilidade de pertencer a qualquer um dos dois grupos (Teste ou Controle).

Pelo fato de este trabalho se tratar de uma pesquisa de campo, fomos à escola, local onde encontramos o sujeito principal de nossa pesquisa. Essa aproximação nos proporcionou um contato maior entre pesquisador e pesquisado, assim como a verificação dos fatos exatamente da forma como eles acontecem dentro do universo que foi observado, a sala de aula, nos moldes que sugere Gonçalves (2001).

A pesquisa foi realizada na Escola X, escola estadual da cidade X. Em 2017, possuía 545 alunos, sendo 287 alunos matriculados nos Anos Iniciais do Ensino Fundamental e 258 alunos nos Anos Finais do Ensino Fundamental. Estruturalmente, a escola dispõe de biblioteca, quadra de esportes coberta, laboratório de ciências, laboratório de informática e internet banda larga, banheiro, dependências e vias adequadas a alunos com deficiência ou mobilidade reduzida. 
A alocação dos alunos nos grupos foi feita por sorteio. Para controlar os alunos que não participaram, ou seja, estavam ausentes no dia do sorteio, sorteamos o próximo aluno para substituí-lo. Os 15 primeiros números sorteados formaram o grupo Teste, e os 15 que sobraram formaram o grupo Controle. Os números sorteados correspondiam ao número do aluno na lista de chamada utilizada pela professora para controle de frequência. Dessa forma, conseguimos identificar a criança e o grupo do qual faria parte. $\mathrm{O}$ mesmo procedimento foi repetido na turma 2.

Foram incluídos no estudo aqueles sujeitos que atenderam aos seguintes critérios: estar matriculado no terceiro ano dos Anos Iniciais do Ensino Fundamental, ter idade entre oito e dez anos, estar alfabetizado, manifestar desejo e concordância na participação da pesquisa. Foram excluídos da pesquisa os alunos das demais séries e turmas que estavam fora da faixa etária estipulada, como também aqueles que não manifestaram desejo e concordância na participação da pesquisa, ou não obtiverem a autorização dos pais ou responsáveis, ou que não estavam presentes na data da aplicação. Outro fator impeditivo foi atribuído aos que possuíam alguma incapacidade que dificultava ou impossibilitava a participação ou realização da pesquisa.

Dos 50 alunos que participaram das atividades da pesquisa, 24 eram do sexo feminino, correspondendo ao percentual de $48 \%$, e 26 eram do sexo masculino, totalizando $52 \%$. Um dado relevante no que se refere ao acesso à TDICs, dentre os pais dos alunos participantes, 99\% afirmam ter telefones celulares com acesso a internet. Os pais afirmam que as crianças também têm acesso a esse equipamento. $\mathrm{O}$ mesmo não acontece com o acesso a desktops, por exemplo.

A pesquisa foi desenvolvida em três etapas. Primeiro, houve a aplicação do pré-teste, que nos possibilitou diagnosticar o nível de conhecimento das palavras constantes no jogo pelos alunos. Pudemos observar as maiores dificuldades e porcentagem de palavras acertadas e erradas.

Segundo, procedemos à aplicação dos jogos Grapphia e Forma palavras na sala de aula. Nosso objetivo foi estimular a memorização das palavras abordadas no conto $A$ fazenda. Nessa etapa, os dados coletados (usuário, palavras apresentadas, taxa de acerto/erro) ficaram armazenados no aparelho celular, numa base de dados destinada a esse fim. Os resultados foram enviados automaticamente para um e-mail criado para recebê-los. Posteriormente, foram inseridos em uma planilha de Excel, na qual foram registrados os nomes dos usuários, as palavras que foram jogadas, bem como os acertos e erros das crianças.

Por último, fizemos uma aplicação do pós-teste, que teve como a finalidade verificar a nossa hipótese de uma maior memorização das palavras após o jogo. Após a realização de todas as etapas, foi possível analisar se, com o uso do aplicativo Grapphia, as crianças desenvolveram com maior facilidade a memorização das palavras trabalhadas em detrimento das que não utilizaram o aplicativo.

\section{Análise e discussão dos resultados}

No que se refere aos testes, inicialmente, foi realizada uma análise descritiva do percentual de acertos por palavra em dois momentos distintos: antes e depois da realização do experimento, qual seja a utilização do aplicativo Grapphia. A Tab.1 apresenta os resultados obtidos no pré-teste. 
Tabela 1 - Percentuais de acerto por palavra

\begin{tabular}{l|r|r}
\hline \multicolumn{1}{c|}{ Palavra } & Pré-teste & Pós-teste \\
\hline Avisa & $36 \%$ & $\mathbf{4 0 \%}$ \\
Avise & $\mathbf{2 6 \%}$ & $42 \%$ \\
Azar & $44 \%$ & $48 \%$ \\
Azul & $64 \%$ & $\mathbf{8 2 \%}$ \\
Besouro & $34 \%$ & $54 \%$ \\
Brasa & $38 \%$ & $60 \%$ \\
Buzina & $40 \%$ & $60 \%$ \\
Casa & $68 \%$ & $\mathbf{8 2 \%}$ \\
Casamento & $44 \%$ & $48 \%$ \\
Corajoso & $50 \%$ & $56 \%$ \\
Cozido & $68 \%$ & $70 \%$ \\
Fantasia & $58 \%$ & $52 \%$ \\
Fazenda & $46 \%$ & $54 \%$ \\
Fazendeiro & $\mathbf{7 2 \%}$ & $\mathbf{8 2 \%}$ \\
Guloseima & $30 \%$ & $44 \%$ \\
Mesa & $50 \%$ & $50 \%$ \\
Música & $54 \%$ & $62 \%$ \\
Natureza & $56 \%$ & $64 \%$ \\
Paisagem & $48 \%$ & $64 \%$ \\
Paraíso & $50 \%$ & $52 \%$ \\
Perigosa & $50 \%$ \\
Presa & $50 \%$ & $58 \%$ \\
Presentes & $48 \%$ & $64 \%$ \\
Raposa & $40 \%$ & $52 \%$ \\
Represa & $32 \%$ & $48 \%$ \\
Rezas & $52 \%$ & $46 \%$ \\
Rosas & $38 \%$ & $46 \%$ \\
Surpresa & $46 \%$ & $56 \%$ \\
Tesoura & $40 \%$ & $50 \%$ \\
Tesouro & $44 \%$ & $64 \%$ \\
Vasos & $54 \%$ & $48 \%$ \\
Visitar & $48 \%$ \\
Vizinhança & $52 \%$ \\
\hline & $56 \%$ \\
\hline
\end{tabular}

Fonte: Elaborado pelas autoras.

De acordo com a tabela 1, a palavra mais acertada antes da utilização dos aplicativos pelos alunos foi fazendeiro, com $72 \%$ de acerto, e a palavra mais errada foi avise, com $74 \%$ de erro (apenas $26 \%$ de acerto). Após o experimento, percebemos que, de modo geral, os percentuais de acerto foram modificados, e as palavras azul, casa e fazendeiro tiveram os maiores percentuais de acerto: todas iguais a $82 \%$. Por sua vez, a palavra avisa foi a mais errada, apresentando apenas $40 \%$ de acerto. Vale ressaltar, entretanto, que, em relação ao pré-teste, essa palavra teve a porcentagem de acertos aumentada. 
Como o objetivo desta pesquisa era verificar se o aplicativo Grapphia contribui para a memorização das palavras, foi realizada uma análise estatística considerando o número de palavras acertadas por aluno. Assim, foram consideradas três etapas de análise. Na primeira etapa, foi realizada uma estatística descritiva dessa variável antes da realização do experimento verificando a comparabilidade dos grupos. Na segunda etapa, foi realizada a aplicação do jogo na escola.

De modo global, antes da utilização do aplicativo Grapphia, os números médio e mediano de palavras acertadas por aluno foram, respectivamente, 15,1 e 15 . Verificamos, também, que $75 \%$ dos alunos acertaram até 19 palavras. Vale a pena ressaltar que o teste foi composto por 33 palavras.

Visando verificar a comparabilidade dos grupos (Teste e Controle), apresentamos na Tabela 2 alguns resultados do número de acertos por aluno antes do experimento. O Gráfico 1, por sua vez, ilustra a comparação dos dois grupos antes da utilização do Grapphia.

Tabela 2 - Estatística Descritivas do número de palavras acertadas no pré-teste

\begin{tabular}{l|r|r|r|r|r|r|r}
\hline \multirow{2}{*}{ Grupo } & \multicolumn{7}{c}{ Estatísticas Descritivas } \\
\cline { 2 - 8 } & Média & $\begin{array}{c}\text { Desvio } \\
\text { padrão }\end{array}$ & Mínimo & $\begin{array}{c}\text { Primeiro } \\
\text { quartil }\end{array}$ & Mediana & $\begin{array}{c}\text { Terceiro } \\
\text { quartil }\end{array}$ & Máximo \\
\hline Controle & 15,4 & 6,0 & 3 & 14 & 14 & 17 & 27 \\
Grapphia & 14,8 & 6,9 & 2 & 10 & 16 & 19 & 24 \\
\hline
\end{tabular}

Fonte: Elaborado pelas autoras.

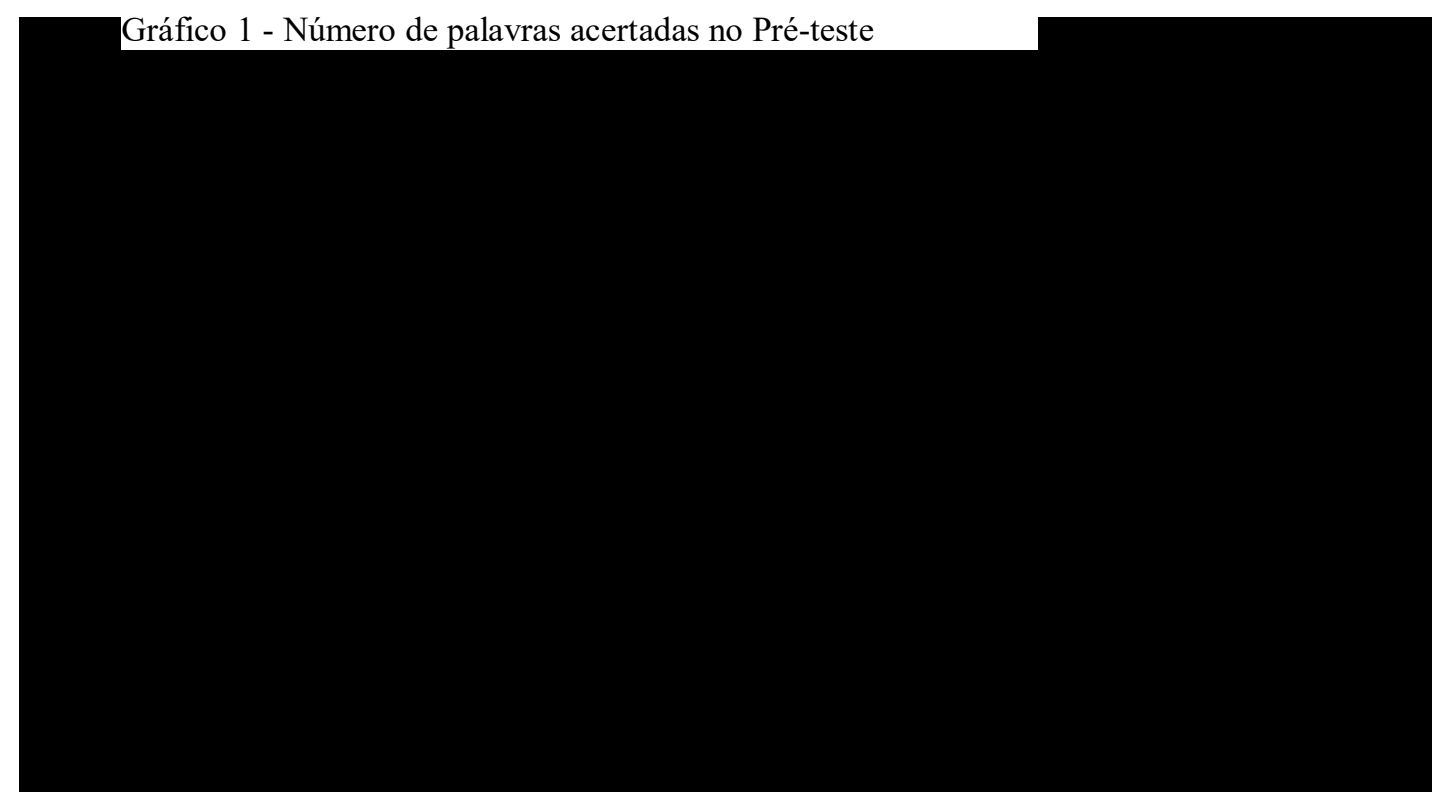

Fonte: Elaborado pelas autoras.

De modo geral, as estatísticas descritivas apresentadas na Tabela 2, bem como a análise do Gráfico 1, não sugerem diferenças entre os dois grupos. Para verificar a existência de diferenças estatisticamente significativas entre eles, foi realizado o teste $t$ para a comparação dos acertos médios. $\mathrm{O}$ valor $p$ encontrado foi igual a 0,7767 e, 
portanto, concluímos que não há diferenças estatisticamente significativas entre os grupos em relação ao número médio de palavras acertadas antes da utilização dos aplicativos.

Várias pesquisas educacionais, como o PISA e o SAEB, mostram que, de modo geral, as meninas têm um desempenho em Língua Portuguesa melhor do que os meninos. Por essa razão, considerou-se importante verificar se existia diferença na composição dos grupos (Teste e Controle) em relação ao sexo. Assim, para finalizar essa etapa a respeito da comparabilidade dos grupos, foi realizado o teste $\mathrm{X}^{2}$, cujo valor $p$ encontrado foi igual a 0,5713 . Portanto, conclui-se que não existem diferenças estatisticamente significativas entre os grupos em relação à distribuição por sexo. Esses resultados são importantes para validar a comparabilidade dos grupos antes do experimento.

Como resultados da segunda etapa de análise, de modo global, depois do experimento, os números médio e mediano de palavras acertadas por aluno foram, respectivamente, 18,2 e 19 . Verificou-se que $75 \%$ dos alunos acertaram até 21 palavras. Comparando esses resultados aos anteriores, percebe-se um aumento no número de acertos depois da realização do experimento. Para verificar se esse aumento pode ser de fato um efeito da utilização do aplicativo Grapphia, procedemos a comparação dos grupos. A Tabela 3 e o Gráfico 2 sumarizam os resultados das estatísticas descritivas do número de palavras acertadas pelos alunos depois da utilização do aplicativo Grapphia.

Tabela 3 - Estatística Descritivas do número de palavras acertadas no Pós-teste

\begin{tabular}{c|c|c|c|c|c|c|c}
\hline \multirow{2}{*}{ Grupo } & \multicolumn{7}{c}{ Estatísticas Descritivas } \\
\cline { 2 - 8 } & Média & $\begin{array}{c}\text { Desvio } \\
\text { padrão }\end{array}$ & Mínimo & $\begin{array}{c}\text { Primeir } \\
\text { o } \\
\text { Quartil }\end{array}$ & $\begin{array}{c}\text { Median } \\
\text { a }\end{array}$ & $\begin{array}{c}\text { Terceiro } \\
\text { Quartil }\end{array}$ & Máximo \\
\hline Controle & 16,8 & 5,5 & 6 & 13 & 16 & 20 & 27 \\
Grapphia & 19,7 & 3,0 & 13 & 18 & 20 & 22 & 26 \\
\hline
\end{tabular}

Fonte: Elaborado pelas autoras.

\section{Gráfico 2 - Número de palavras acertadas no Pós-teste}

Fonte: Elaborado pelas autoras.

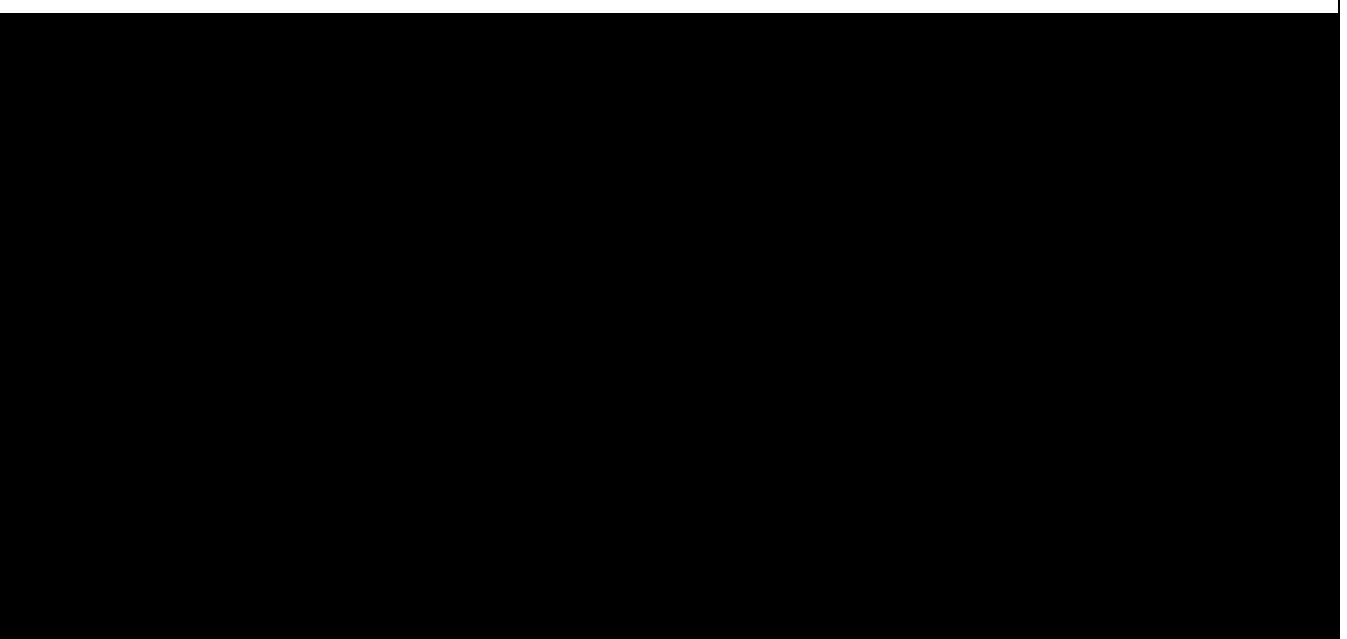

- 
Verificamos, assim, que os resultados mostram um desempenho melhor dos alunos do grupo Teste, quando comparados aos do grupo Controle, depois da realização do experimento. Para verificar a existência do efeito do aplicativo Grapphia no número médio de palavras acertadas pelos alunos, foi realizado o teste $t$. $\mathrm{O}$ valor $p$ encontrado foi estatisticamente significativo, igual a 0,02293. Assim, conclui-se que os alunos que utilizaram o aplicativo Grapphia acertaram mais palavras do que os alunos do grupo Controle. Podemos inferir, então, que o aplicativo desenvolvido possui um efeito de aumentar o número médio de palavras acertadas. Em média, em um teste de 33 questões, os alunos que usaram o aplicativo Grapphia acertaram em torno de 3,0 palavras a mais que os alunos do grupo Controle.

\section{Considerações finais}

Buscamos argumentar neste trabalho que o ensino-aprendizagem da ortografia é um assunto relevante, mas que conta com poucas produções científicas que abordam o estudo das irregularidades ortográficas, bem como metodologias para tratar o assunto na sala de aula. Verificamos, com base nos resultados obtidos que, para crianças de 8 anos, o aplicativo apresentou resultados positivos e estatisticamente relevantes no que diz respeito a uma maior memorização das palavras que possuem relação irregular entre grafema-fonema. Esses resultados podem ser um indício de que a hipótese sobre o ensino-aprendizagem das irregularidades ortográficas a partir de jogos que proporcionam uma aprendizagem de forma lúdica, a partir de mecanismos que estimulam a memorização (ALVARENGA, 1995), pode ser um caminho acertado.

É válido ressaltar que outro possível acerto está relacionado à escolha do celular como suporte do jogo Grapphia. O aparelho mostrou ser acessível e de fácil manuseio, por estar presente na realidade de $99 \%$ dos alunos que contribuíram para os resultados desta pesquisa. No entanto, apesar dos benefícios gerados por uma utilização planejada e adequada dessa tecnologia, ainda encontramos certa resistência por parte dos docentes para a utilização de dispositivos móveis em sala de aula.

Muitas vezes essa resistência pode ser gerada pela falta de formação, pela falta de informação ou mesmo pela dificuldade de alguns pais de disporem de seu único aparelho celular para que a criança o leve para a escola, quando essa não possui um número de aparelhos que possa atender a todos os alunos. Desse modo, tomamos como desafio adaptar a versão do Grapphia, para utilização em desktops, que é a tecnologia disponível na escola parceira.

É pertinente salientar que o aplicativo foi testado pela primeira vez, e os resultados já nos permitem ter uma visão para além da aprendizagem eficaz. Com o objetivo de levar uma educação de qualidade ao maior número de crianças possível, temos, ainda, que vencer alguns desafios, tais como:

a) encontrarmos meios que atendam às questões de acessibilidade nas suas mais variadas formas;

b) atentarmos às questões raciais, para que as crianças consigam se reconhecer nos personagens do conto;

c) atentarmos em relação aos contos, para que as crianças consigam reconhecer sua realidade. 
De modo a trazermos mais contribuições para a discussão do tema, salientamos a importância de construirmos reflexões sobre o ensino da ortografia, a fim de evitar que seu ensino se restrinja à metodologia de repetições, ditados, reescritas, que não esclarecem ao aluno o motivo dos desvios que comete. Por fim, os resultados desta pesquisa nos sugerem que o aplicativo Grapphia é relevante para aumentar o número de palavras memorizadas pelos alunos. Dessa maneira, vislumbramos que ele se torne uma ferramenta para o professor no processo de ensino-aprendizagem da ortografia.

\section{Referências}

ALVARENGA, D. Análise das variações ortográficas. Presença Pedagógica, Belo Horizonte, ano 1, v 2, p. 25-34, mar./abr. 1995.

AUTOR Y. 2017.

BARBOSA, P. M. F.; BERNARDES, N. G. B.; MISORELLI, M. I.; CHIAPPETTA, A. L. de M. L. Relação da memória visual com o desempenho ortográfico de crianças de $2^{\mathrm{a}}$ e $3^{\text {a }}$ séries do ensino fundamental. Revista $C E F A C$, v. 12, n. 4, p. 598-607, jul./ago. 2010. Disponível em:

http://www.scielo.br/pdf/rcefac/v12n4/09.pdf. Acesso em: 9 de junho de 2018.

BELLONI, M. L. Educação a distância. 5. ed. Campinas: Autores Associados, 2008.

BRASIL. Ministério da Educação. Secretaria de Educação Fundamental. Parâmetros curriculares nacionais: ensino fundamental - introdução. Rio de Janeiro: DP\&A, 1997.

CAGLIARI, L. C. Alfabetização e Lingüística. 10ª ed. São Paulo: Scipione, 2005.

DEMO, P.. Os desafios da linguagem do século XXI para o aprendizado na escola. Palestra, Faculdade OPET, junho 2008. Disponível em < https://caldeiraodeideias.wordpress.com/2009/08/05/pedro-demo-aborda-os-desafiosda-linguagem-no-seculoxxi/\#: :text=O\%20tema $\% 20 \mathrm{de} \% 20$ sua $\% 20$ palestra,para $\% 20 \mathrm{a} \% 20$ aprendizagem $\% 20$ na \%20escola $\%$ E2\%80\%9D.\&text=Algumas $\% 20$ crian $\% \mathrm{C} 3 \% \mathrm{~A} 7 \mathrm{as} \% 20 \mathrm{t} \% \mathrm{C} 3 \% \mathrm{AAm} \% 20 \mathrm{a}$ cesso $\% 20 \% \mathrm{C} 3 \% \mathrm{~A} 0$, que $\% 20$ aprendem $\% 20$ melhor $\% 20$ na $\% 20$ internet. $>$. Acesso em 9 de junho de 2018.

GONÇALVES, E. P. Iniciação à pesquisa científica. Campinas: Alínea, 2001.

LEMLE, M. Guia teórico do alfabetizador. 17. ed. São Paulo: Ática, 2009.

MARCONI, M. de A.; LAKATOS, E. M. Metodologia do trabalho científico. 7. ed. São Paulo: Atlas, 2008. 
MATTAR, J. Games e educação: como os nativos digitais aprendem. São Paulo: Pearson, 2010.

MORAIS, A. G. de. Ortografia: ensinar e aprender. São Paulo: Ática, 2003.

MORAIS, A. G. de. A norma ortográfica do português: o que é? para que serve? Como está organizada? In: SILVA, A., MORAIS; A. G.; MELO, K. L. R. Ortografia na sala de aula. Belo Horizonte: Autêntica, 2007.

ROJO, R. Escola conectada: os multiletramentos e as TIDCs. São Paulo: Parábola, 2013.

AUTOR X, 2019.

TRIOLA, Mario F. Introdução à estatística: atualização da tecnologia. Rio de Janeiro: Ltc, 2013.

ZORZI, J. L. Aprendizagem e distúrbios da linguagem escrita: questões clínicas e educacionais. Porto Alegre: Artmed, 2003.

Recebido em 08 de setembro de 2020

Aceito em 04 de novembro de 2020 